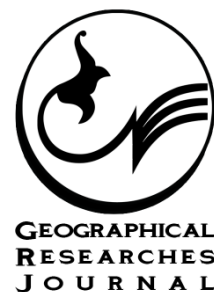

\title{
Evaluating and Analyzing the Spatial Justice in the Distribution of Sports Applications and Services in Garmsar County
}

\section{ART I C L E I N F O}

\section{Article Type}

Original Research

\section{Authors}

Khajoo M. ${ }^{1} M A$

Tayebi Sani SM. ${ }^{* 1} P h D$

Fahiminejad A. ${ }^{1} P h D$,

Morsal B. ${ }^{1} P h D$

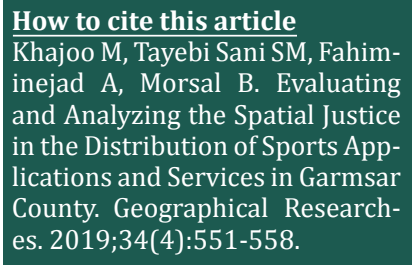

${ }^{1}$ Department of Physical Education, Faculty of Humanities, Shahrood Branch, Islamic Azad University, Shahrood, Iran

\section{*Correspondence}

Address: IAU Shahrood Branch, University Boulevard, Shahrood, Iran Phone: +98 (21) 88445901 Fax: +98 (21) 88546377 tayebi.sani@gmail.com

\section{Article History}

Received: June 29, 2019

Accepted: August 25, 2019

ePublished: December 11, 2019

\section{A B S T R A C T}

Aims \& Backgrounds The present study analyzes the spatial location of sports facilities and assessing the access to sports centers according to their spatial distribution pattern at the level of communication networks in Garmsar County. The main purpose is to identify the distribution and distribution status of sports applications in the city and determine the shortcomings and needs.

Methodology This research is an applied and descriptive - analytic method. After determining the per capita consumption of sport in the Garmsar County, using the Williamson model, the distribution per capita of these centers was measured at the district level according to population density. In the second part, using the Moran model, the spatial distribution pattern of sports applications (outdoor, indoor and all sports) was measured based on the area of these applications.

Findings The results indicate that the sports spaces in Garmsar city are 0.79 square meters he total per capita sports space per household is about 2.11 square meters. Also, per capita related to outdoor sports spaces are more than per capita for indoor spaces ( 0.65 vs. 0.23 square meters per person). Meanwhile, the total sports space in Iwanki is higher than Garmsar ( 0.839 versus 0.619 ). This is while the population density of Garmsar is 10.35 and Iwanki is 4.58 . Thus, with increasing population density, the total area of sports spaces (open and covered) decreases with the slope of the line R2 $=0.5985$.

Conclusion Results indicates that managers and planners are not paying attention to social justice in the distribution of sports spaces in the study area.

Keywords Social Justice; Sport Services Usage; Spatial Distribution; Sports Per Capita; Garmsar County

\section{CIT A T I O N L INKS}

[CESCS; 2012] Council of europe social cohesion and sport examples of good practice from member countries of the...; [Cleland, et al; 2010] Do the individual, social, and environmental correlates of physical activity differ between urban and ...; [Dixon \& Ramutsindela; 2006] Urban resettlement and environmental justice in Cape ...; [Ebrahimi \& Mehdipour; 2016] The effect of sport infrastructure and demographic characteristics on the level of sports participation of Ahwazi citizens ...; [Ebrahimzadeh \& Mojir Ardakani; 2006] An evaluation of land use in Ardakan city, Fars ...; [Hamidi, et al; 2018] Designing and developing a strategic plan of the Iranian student sport ...; [Hallmann, et al; 2011] Interdependency of sport supply and sport demand in German metropolitan and medium-sized municipalities-findings from multi-level ...; [Hewko; 2001] Spatial equity in the urban environment: Assessing neighborhood accessibility to public ...; [Hosseini, et al; 2013] Locating port places using geographic information system (GIS); case study: Saqez ...; [Humphreys \& Ruseski; 2010] The economic choice of participation and time spent in physical activity and sport in ...; [Kaphle; 2006] Evaluating people's accessibility to public parks using geographic information systems: A case study ...; [Lotfi \& Koohsari Mohammad; 2009] Measuring objective accessibility to neighborhood facilities in the City a case study: Zone 6 in Tehran, ...; [Martinez; 2009] The use of GIS and indicators to monitor intra-urban inequalities a case Rosario, ...; [Mitchel \& Norman; 2012] longitudinal environmental justice analysis: Co-evolution of environmental quality and deprivation in ...; [Namazi \& Hosseini; 2018] Spatial analysis of sports venues and assessment of access to these centers according to their spatial distribution pattern at the communication network ...; [Oh \& Jeong; 2007] Assessing the spatial distribution of urban parks using ...; [Pacione; 2005] Urban geography a global ...; [Peymanfar, et al; 2012] A survey on obstacles to the development of public sports in the ...; [Rasekh, et al; 2015] The design of a strategic plan for Iran female ...; [Roostaei, et al; 2013] The assessment of spatial justice in the distribution of urban ...; [Sohrabi, et al; 2011] An investigation of accessibility, closeness and building of sports areas in Uroumieh ...; [SCI; 2019] Statistical center of ...; [Tadjoeddin, et al; 2003] Aspiration to inequality: Regional disparity and center regional conflicts in ...; [Tsou, et al; 2005] An accessibility-based integrated measure of relative spatial equity in urban ...; [Vandian \& Ebrahimi; 2013] Offering of suggestion model for site selection of sport place by incorporation multi-criteria decision making methods (MCDM) and ...; 
خدمات مهم در سطح شهرها، كاربرى ورزشى است؛ جرا كه هر مكان ورزشى كه براى فعاليت جسمانى، تفريح يا ورزش ساخته شانه شانه

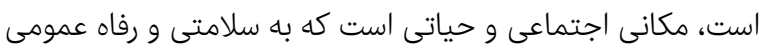

افراد جامعه كمك ميكند [Vandian, 2013] برخى موانع و مشكلات ساختارى و محتوايى سبب كاهش

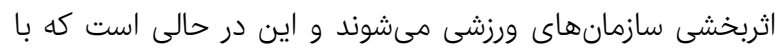
مطالعه و بررسى وضعيت موجود و تعيين نقاط قوتى فران، ضعفى

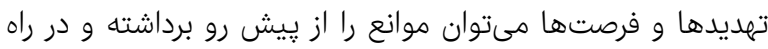
ي ييشرفت كام نهاد [Rasekh, 2015]. در جهان كنونى، توسعها

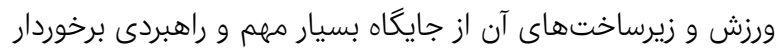

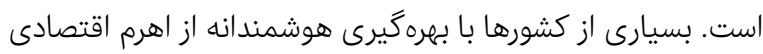

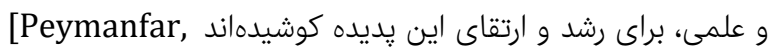

קكونكى توزيع فضايى و مكانى كاربرىها يكى از مهمترين

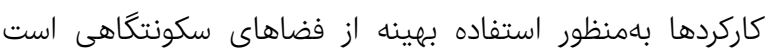

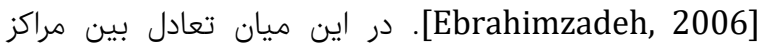

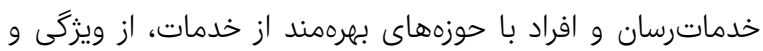
عناصر مهم محسوب مىشود [Hosseini et al, 2013]. اساساً

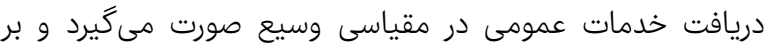

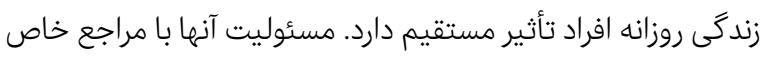

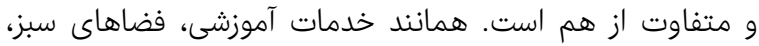

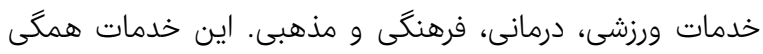

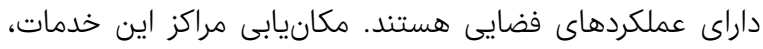

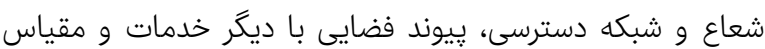
نهادهاى حمايتكننده و غيره از خصوصيات فيكائ فضايى آنها محسوب

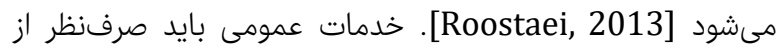

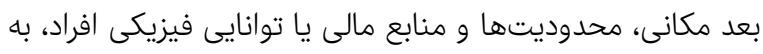

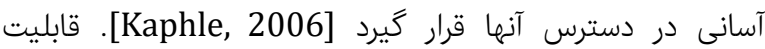

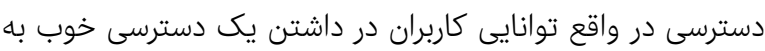

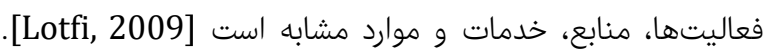

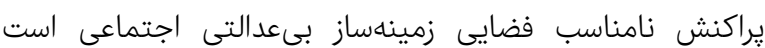

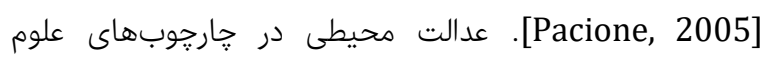

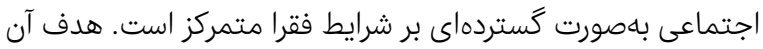

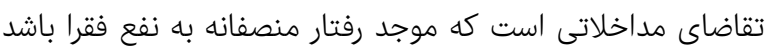

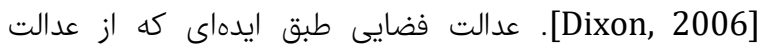

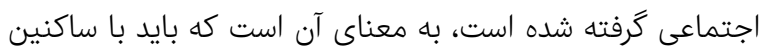

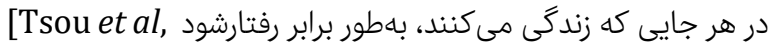
[2005. عدالت فضايى نقطه تلاقى فضا و عدالت الت اجتماعى است؛

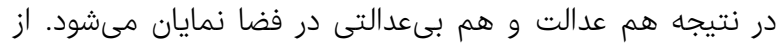
اينرو، تجزيه و تحليل بر همكنش بين فين فضا و و اجتماع در فهم

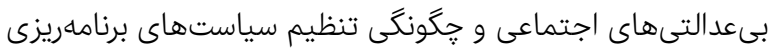

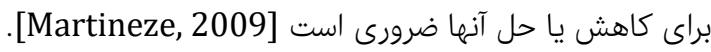

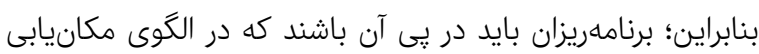

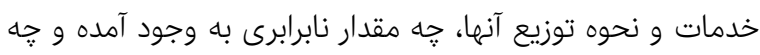

ارزيابى و تحليل عدالت فضايى در يراكنش كاربرىها و خدمات ورزشى در شهرستان گرمسار

MA مثده خجو

كروه تربيت بدنى، دانشكده علوم انسانى، دانشگاه آزاد اسلامى واحد شاهرود، شاهرود، ايران

PhD * سيدمصطفى طيبى ثانى

گروه تربيت بدنى، دانشكده علوم انسانى، دانشگاه آزاد اسلامى واحد شاهرود، شاهرود، ايران

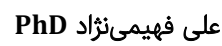

گروه تربيت بدنى، دانشكده علوم انسانى، دانشگاه آزاد اسلامى واحد شاهرود،

شاهرود، ايران

PhD باقر مرسل

گروه تربيت بدنى، دانشكده علوم انسانى، دانشگاه آزاد اسلامى واحد شاهرود، شاهرود، ايران

جكيده

اهداف و زمينهها: يزوهش حاضر به تحليل فضايى اماكن ورزشى و نيز ارزيابى

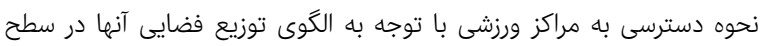

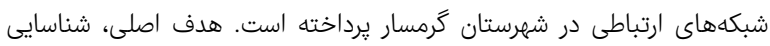
وضعيت يراكنش و توزيع كاربرىهاى ورزشى در اين شهرستان و تعيين كمبودها

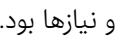
روششناسى: در اين يزوهش توصيفى- تحليلى، يس از تعيين سرانه كاربرىهاى

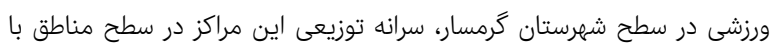

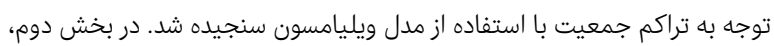

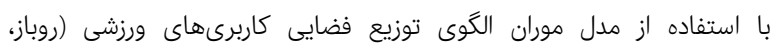

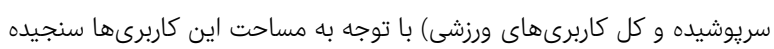

يافتهها: سرانه فضاهاى ورزشى در شهرستان گرمسار برابر با V9/مترمربع بود.

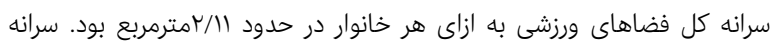

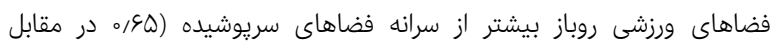

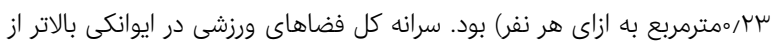

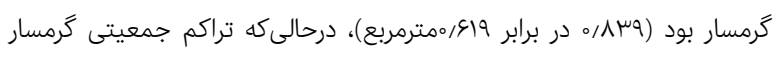

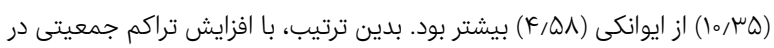

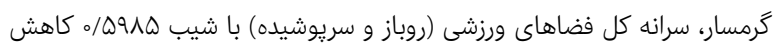
داشت. نتيجهگيرى: نتايج نشاندهنده عدم توجه مديران و برنامهريزان به عدالت اجتماعى در يراكنش فضاهاى ورزشى در منطقه مطالعاتى است. نشان.

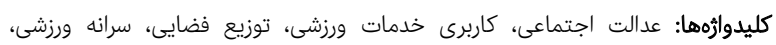

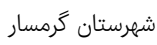

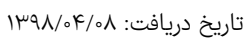

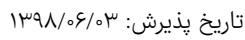

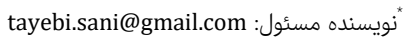

مقدمه

يراكنش صحيح اماكن و فضاهاى ورزشى از جمله مهمترين عوامل مقدمل

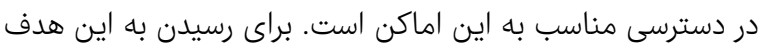

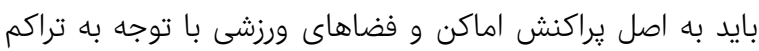
جمعيتى توجه ويزه نمود [Oh, 2011]. يكى از كاربرىها و 
هدف اصلى تحقيق، ارزيابى يراكنش فضايى خدمات و كاربرىهاى ورزشى در شهرستان گرمسار واقع در استان سمنان است.

\section{روش}

محدوده مطالعاتى شهرستان گرمسار از استان سمنان است كه

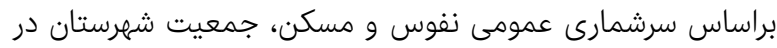

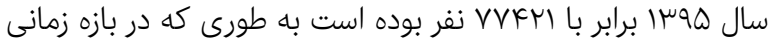

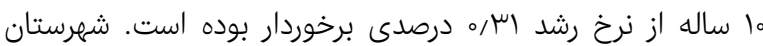

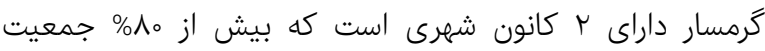

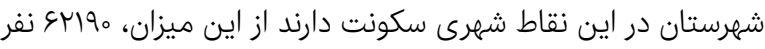

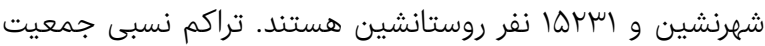

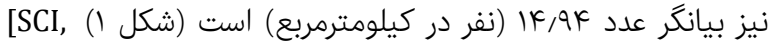

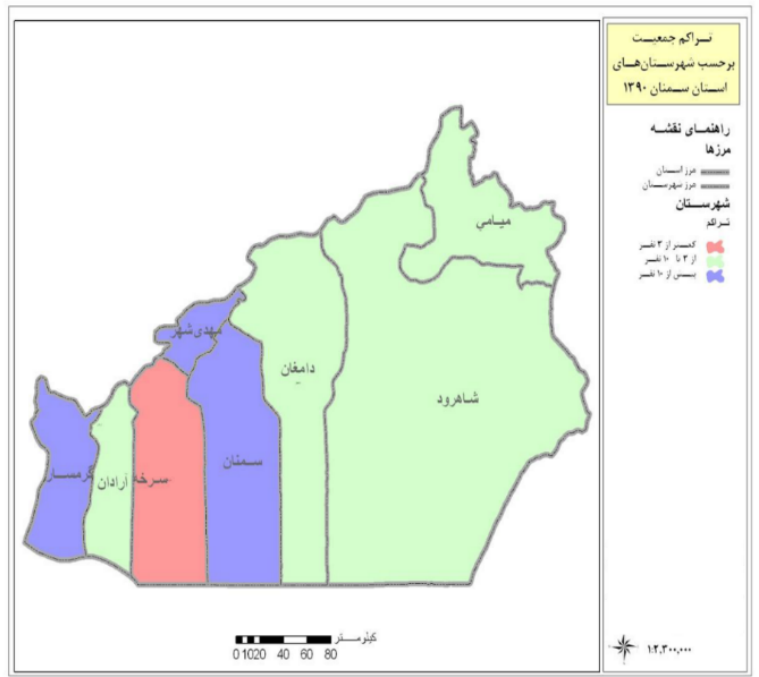

شكل () موقعيت مكانى و تراكم جمعيتى شهرستان گُرمسار در بهينه استان

اين تحقيق از نوع كاربردى است كه با روش توصيفى- تحليلى انجام

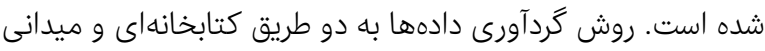

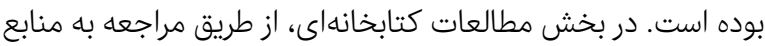
مكتوب، اسناد، مدارك و سالنامههاى آمارى اقدام به تهييه اطلاعات

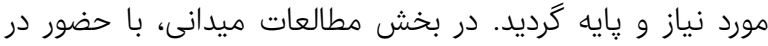

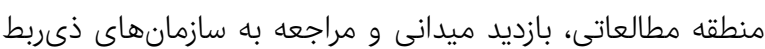

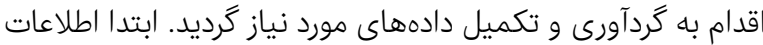

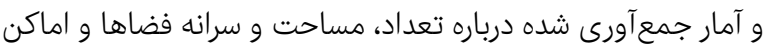
ورزشى سريوشيده و روباز و كل بهصورت دادههاى تصويرى تنظيم

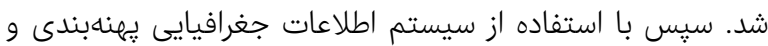

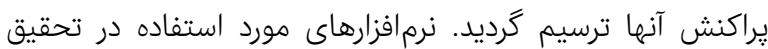

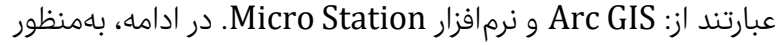
سهولت اجرا، محدوده شهرستان موردمطالعه به 1 منطقه تقسيم

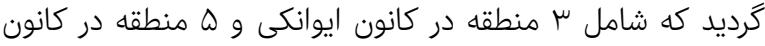

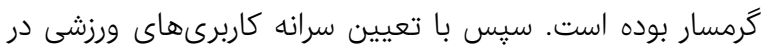

مقوله عدالت محيطى بلهنوان موضوعى كليدى و يراهميت در

يارادايم توسعه پايدار نيز مطرح است [Mitchel, 2012].

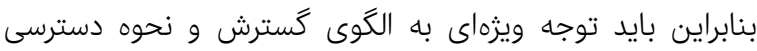
شهروندان به اين كاربرىها صورت گيرد و مسائلى از جمله بـائه ساماندهى مكانى فضايى و توجه به دسترسى مناسب به به اين

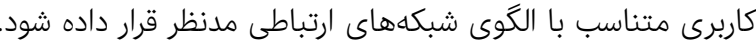

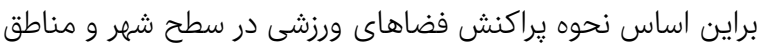
ييرامونى آن مىتواند در الكوى مطلوب كارايى عملكردى شهر تأثير

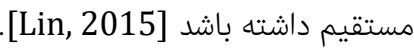
مكانيابى بهينه و دسترسى مناسب به بهاست اماكن ورزشى از اهميت

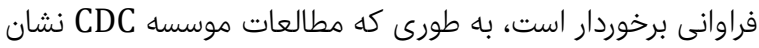

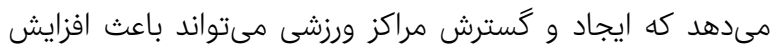

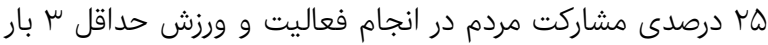

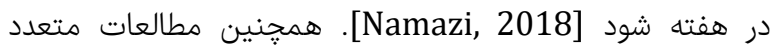

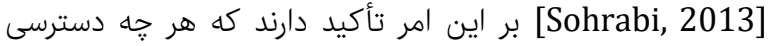
مناسب و راحت به مكانهاى مخصوص ورزش نظير زمينهاى ورزشى، ورزشگاهها و ياركها وجود داشته باشد، مردم تمايل

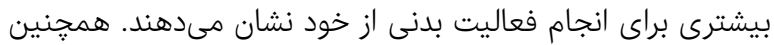
مطالعات متعدد نشان داد افزايش امكانات ورزشى و دسترسى آسان آسان به اين مراكز و همجوارى بهتر اين مكانها با ساير كاربرىهاى

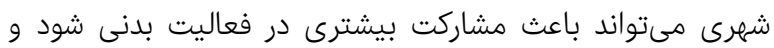

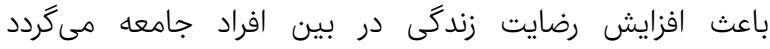
[Humphreys, 2010; Hallmann, 2011; Cleland, 2009; .Ebrahimi, 2016] امروزه فراگيرشدن ورزش باعنوان ابزارى براى توسعه در ابعاد

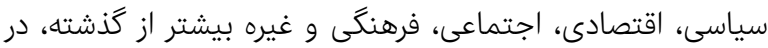

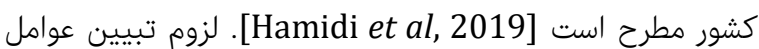
مؤثر در رشد و توسعه اين ابزار مىتواند در نيل به اهداف و سياستهاى استراتزيك كشور مؤثر واقع شود. علاوه بر آن، در ايران آنوان

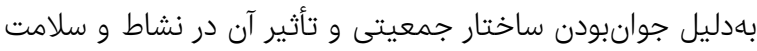
عمومى، ورزش اهميتى دوجندان يافته است.

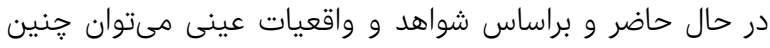
عنوان نمود كه وضعيت كمى و كيفى ورزش در استان سمنان و و وريان

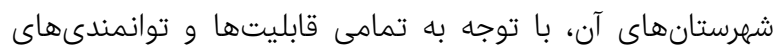

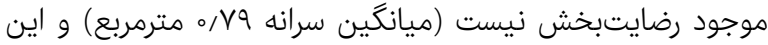

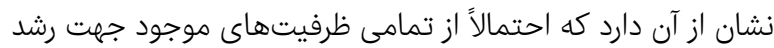

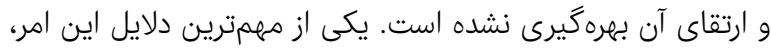

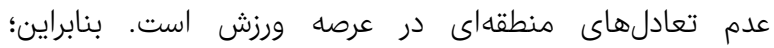
بازشناسايى يتانسيلها و امكانات و نيز تعيين نقاط قوت و ضعف

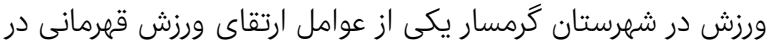

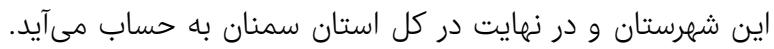

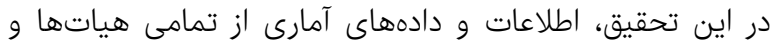

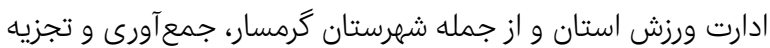


متغير است. ارزش نزديك به ا نشان مىدهد كه بهطور كلى نواحى

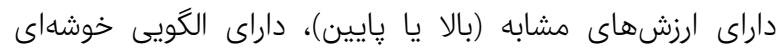

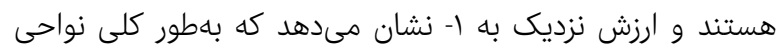

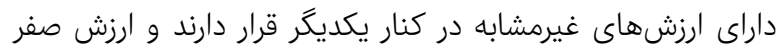
نيز نشان دهنده الگويى تصادفى است. شاخص موران مطابق رابطه دريه

$$
\text { زير تعريف مىشود: }
$$

$I=\frac{{ }^{n} \sum_{i=1}^{n} \sum_{j=1}^{n} W i, j Z i Z j}{\sum_{i=1}^{n} Z_{I}^{2}}$

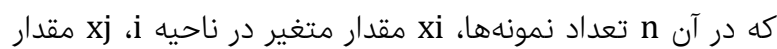

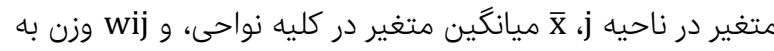

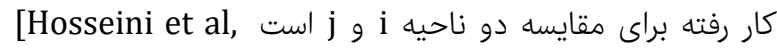

\section{يافتهها}

براساس روششناسى تحقيق و دادههاى آمارى موجود اقدام به

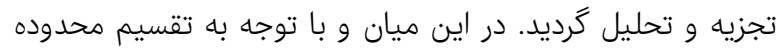

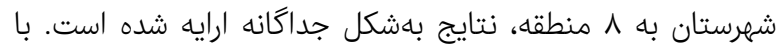

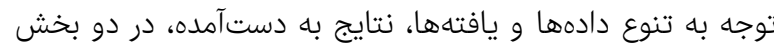
جداگانه ارايه مىشوند.

\section{وضعيت سرانههاى ورزشى در شهرستان گرمسار}

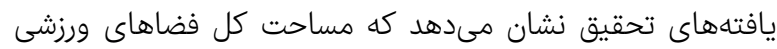

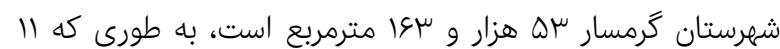

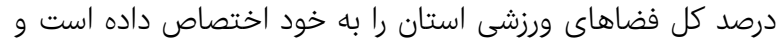

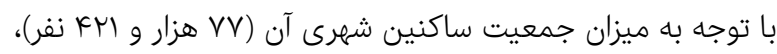

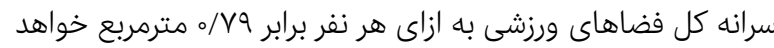

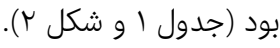

سطح شهرستان گرمسار، با استفاده از مدل ويليامسون سرانه توزيعى اين مراكز در سطح مناطق با توجه به تراكم جمعيت سنجيده شد.

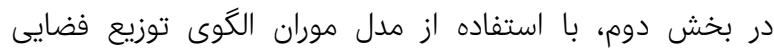

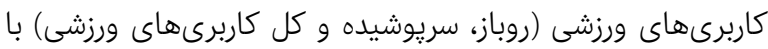

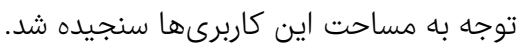

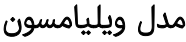
براساس اين مدل نابرابرىهاى منطقهاى تعيين خواهد شد. بهكمك

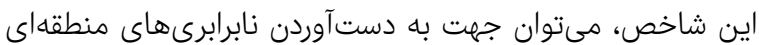

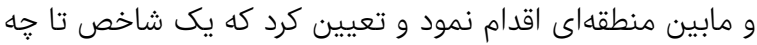

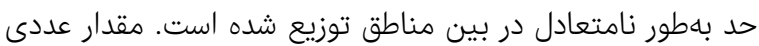

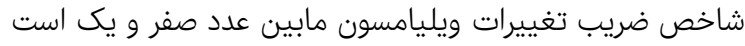

كه هر گهه قدر رقم به دستآمده به سمت صفر گرايش يابد نشاندهنده كاهش نابرابرىهاى منطقهاى است. فرمول زير بيانكر اين رابطه است [Tadjoeddin, 2003]:

$V i=\frac{\sqrt{\sum_{i}^{n}\left(Y i-Y^{-}\right) 2 \frac{f i}{p}}}{Y^{-}}$

جمعيت در منطقه و Pi جمعيت كل است. Yi سرانه NDVI و N تعداد كل مناطق است.

شاخص موران (Moran's I)

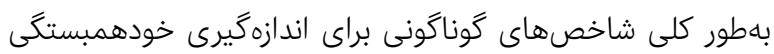

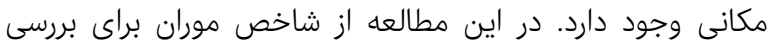

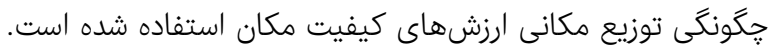

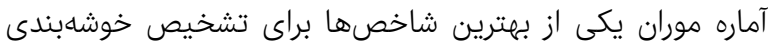

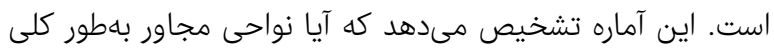
داراى ارزشهاى مشابه يا غيرمشابه هستند. ارزش موران بين إو ا-

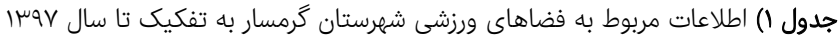

\begin{tabular}{|c|c|c|c|c|}
\hline استان سمنان & كانون جمعيتى ايوانكى & كانون جمعيتى گرمسار & شهرستان گرمسار & متغيرها/ آمارهها \\
\hline rII & 9 & 10 & MK & تعداد كل فضاهاى ورزشى (باب) \\
\hline $8 \Lambda$ & $\mu$ & $\checkmark$ & 10 & تعداد فضاهاى ورزشى روباز (باب) \\
\hline lkr & $\Delta$ & 9 & ik & تعداد فضاهاى ورزشى سريوشيده (باب) \\
\hline$\Delta \mu_{0} \cdot k V k$ & 19948 & 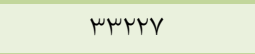 & QHISH & مساحت كل فضاهاى ورزشى (مترمربع) \\
\hline rлlras & IITVK & remok & rVQVe & مساحت فضاهاى ورزشى روباز (مترمربع) \\
\hline IkqIVA & 1s\&4 & sarm & $10 \Delta \wedge \mathrm{V}$ & مساحت فضاهاى ورزشى سريوشيده (مترمربع) \\
\hline Vor.ms. & rmpks & QHEVQ & VVKMI & تعداد جمعيت شهرستان (نفر) \\
\hline$\circ / \mathrm{VQ}$ & $\circ / \wedge \mu q$ & $\circ / 919$ & $\circ / \mathrm{V} q$ & سرانه كل فضاهاى ورزشى (به ازاى هر نفر) \\
\hline$\circ / \Delta K$ & $0 / k V k$ & $0, k q$ & ०/QS & سرانه فضاهاى ورزشى روباز (به ازاى هر نفر) \\
\hline$\circ / M 1$ & ع بره & olr & $\circ / \mu \mu$ & سرانه فضاهاى ورزشى سريوشيده (به ازاى هر نفر) \\
\hline ML.MIK & $\checkmark \gamma^{\mu} \gamma$ & IVFA9 & rQTYS & تعداد خانوار \\
\hline r/AS & r/QV & $1 / 19$ & $r / 11$ & سرانه كل فضاهاى ورزشى (به ازاى هر خانوار) \\
\hline $1 / V V$ & $1, F Q$ & $1 / 0$ & $1 / 49$ & سرانه فضاهاى ورزشى روباز (به ازاى هر خانوار) \\
\hline.$/ 99$ & $1 / 1$ & $\circ / \pi q$ & o/gr & سرانه فضاهاى ورزشى سريوشيده (به ازاى هر خانوار) \\
\hline
\end{tabular}




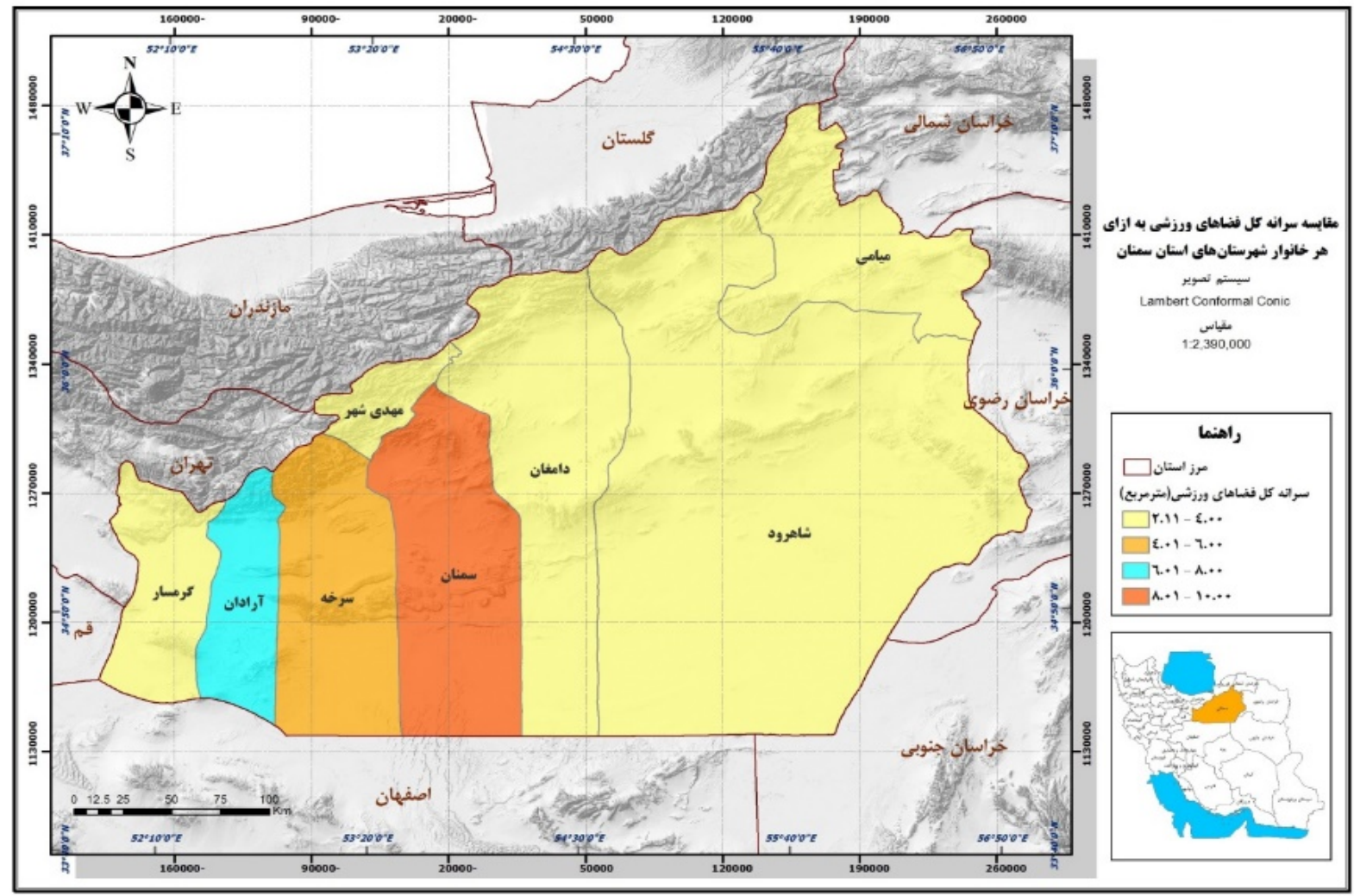

شكل r) مقايسه سرانه كل فضاهاى ورزشى به ازاى هر خانوار در شهرستان گَرمسار با ساير شهرستانهاى استان سمنان

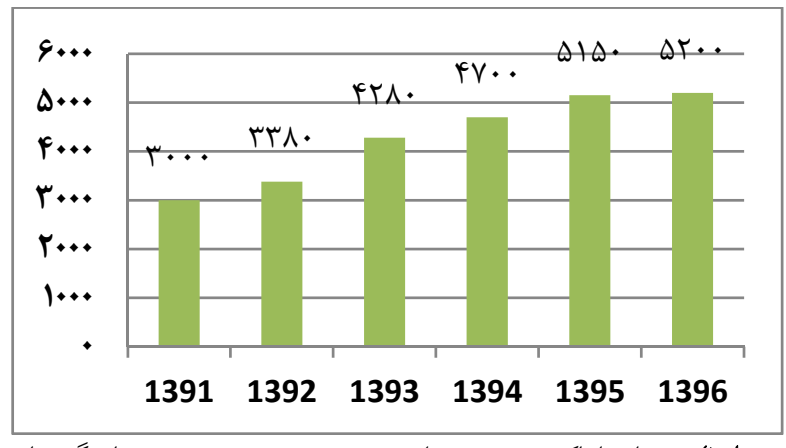

نمودار () تغييرات اماكن ورزشى متعلق به بخش خصوصى در شهرستان گرمسار

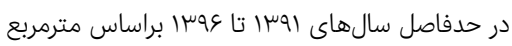

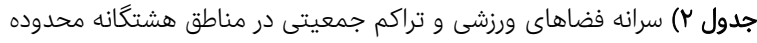
مطالعاتى

\begin{tabular}{|c|c|c|c|c|}
\hline جمعيتى تراكم & ورزشى سريوشيده فضاهاى & $\begin{array}{c}\text { سرانه فضاهاى } \\
\text { ورزشى روباز } \\
\text { (مترمربع) }\end{array}$ & 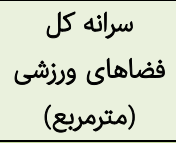 & منطقه \\
\hline$\Delta / 1$ & س & $\circ / \Delta 1 \Lambda$ & $0 / 9$ & I1 \\
\hline k八 & $0 / 41$ & $0, k \mu q$ & o/Al & I2 \\
\hline$k, q$ & $0 / k$ & $0, k<q$ & ס/N & I3 \\
\hline $11 / 00$ & גוMA & $\circ / \Delta 1$ & $\circ / V Y$ & G1 \\
\hline$Q / Q 1$ & r & - Q Q & oIVE & G2 \\
\hline $10 / 11$ & ॰ & $0 / 4 \lambda$ & $\circ / \Delta 1$ & G3 \\
\hline $10 / 94$ & ०/lV & $0 \leqslant \Delta$ & $0 / 4 V$ & G4 \\
\hline $9 / 0$ & o/r & $0, k q$ & س & G5 \\
\hline
\end{tabular}

در نمودار ا، روند افزايشى مساحت فضاهاى ورزشى مربوط به بخش

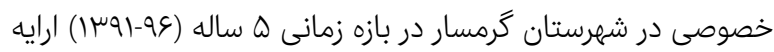
شده است.

بيشترين فضاهاى ورزشى سريوشيده سبرrو\% در مناطق شهرى، و و

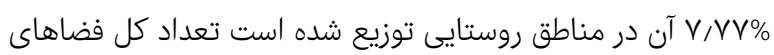
ورزشى در شهرستان گرمسار بk باب است كه از اين تعداد ها ها مورد

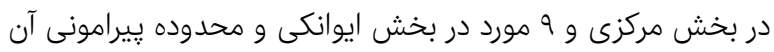
مستقر هستند. مساحت كل فضاهاى ورزشى در شهرستان گرمسار

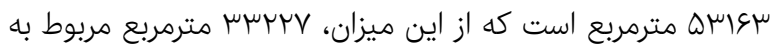

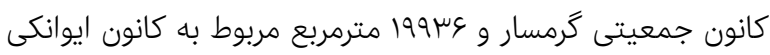
است. از سوى ديكر، مساحت فضاهاى ورزشى روباز در كل شهرستان ونان

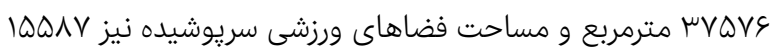

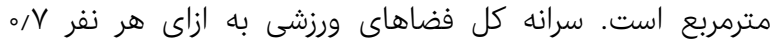

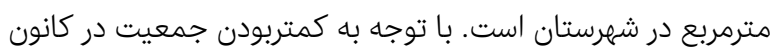

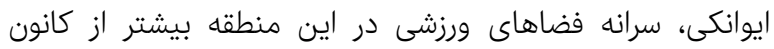

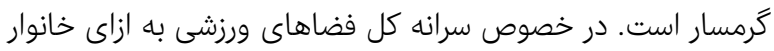
نيز وضعيت به همين گونه است به نحوى كه كانون ايوانكى داراى دراى

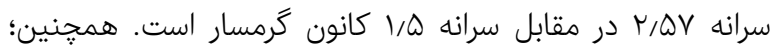

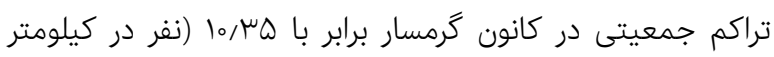

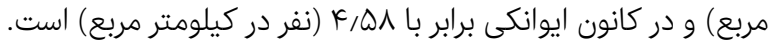

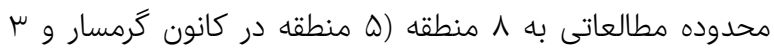

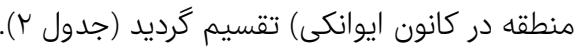




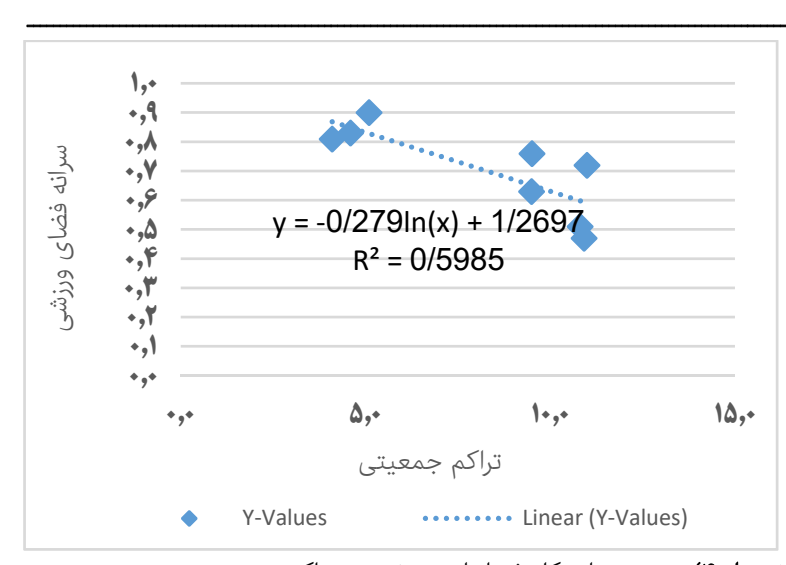

نمودار F) نسبت سرانه كل فضاهاى ورزشى به تراكم جمعيت

جدول سا) وضعيت توزيع مراكز ورزشى در سطح شهرستان گرمسار براساس مدل

ويليامسون جدول

\begin{tabular}{|c|c|c|}
\hline ضريب & موقعيت & كد ناحيه \\
\hline $0 / 90$ & كانون ايوانكى & I1 \\
\hline$\circ / \Lambda$ & كانون ايوانكى & I2 \\
\hline .010 & كانون ايوانكى & I3 \\
\hline $0 / 9 V$ & كانون گُرمسار & G1 \\
\hline ו ו ו & كانون گرمسار & G2 \\
\hline $0 / \& k$ & كانون گرمسار & G3 \\
\hline $0 / 01 \mu k$ & كانون گرمسار & G4 \\
\hline ००VG & كانون گُرمسار & G5 \\
\hline & كل & \\
\hline
\end{tabular}

ارزيابى الكويى فضايى براكنش مراكز ورزشى كانى بهمنظور بررسى تغييرات مكانى ارزشهاي كائ كيفيت مكان و ش شناسايى

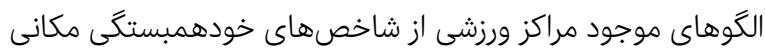

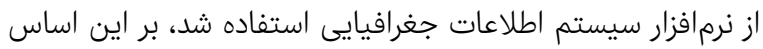

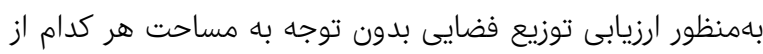

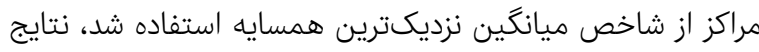

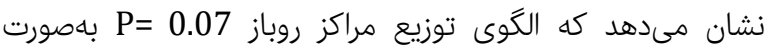

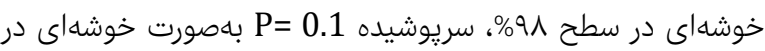

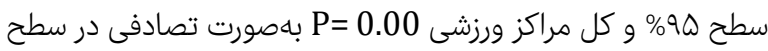

است است

با مقايسه نتايج حاصل از شاخص ميانكين نزديكترين همسايه و

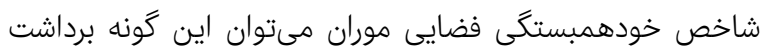

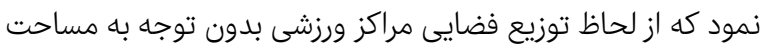

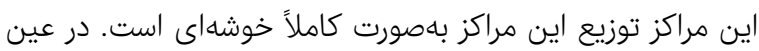

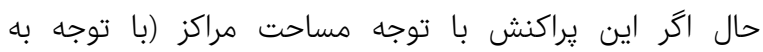
خدماتدهى بيشتر) سنجيده شود، الكوى توزيع اين مراكز بهاصورت

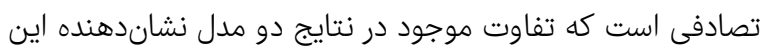

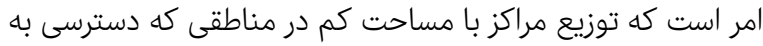

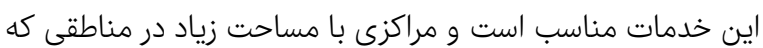

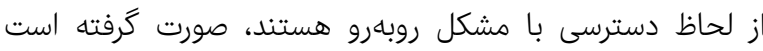

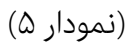

نتايج بيانكر آن است كه با افزايش تراكم جمعيت، سرانه فضاهاى

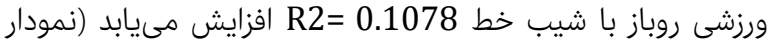
از سوى ديكر، با افزايش تراكم جمعيت، سرانه فضاهاى ورزشى

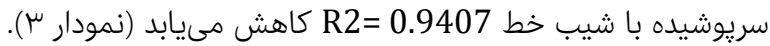

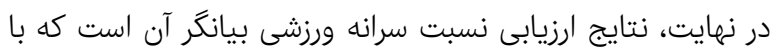

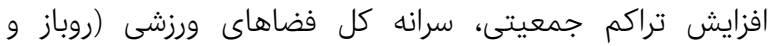

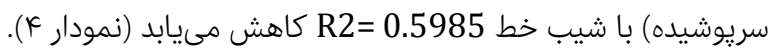

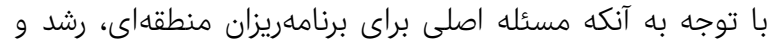
توسعه مناطق است و بررسى عدم توزيع متناسب فضائ ترايى امكانات

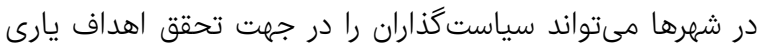

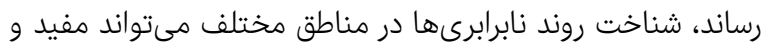

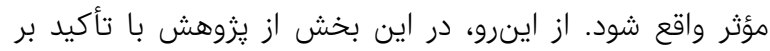

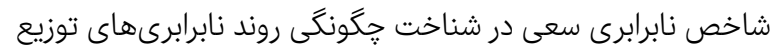
مراكز ورزشى موجود در سطح مناطق شعر گرمسار با استفاده از مدل ويليامسون شده است.

نتايج درج شده در جدول ب نشانكر آن است كه توزيع فضايى مراكز

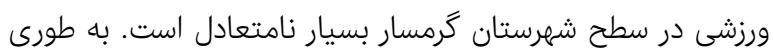

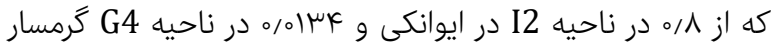

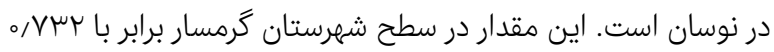

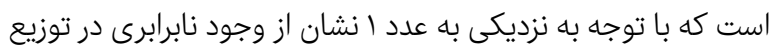
خدمات ورزشى در سطح شهرستان گرمسار دارد (جدول س). $\mathrm{Vi}=\frac{\sqrt{\sum_{\mathrm{i}}^{\mathrm{n}}\left(\mathrm{Yi}-\mathrm{Y}^{-}\right) 2 \frac{\mathrm{fi}}{\mathrm{p}}}}{\mathrm{Y}^{-}}=0.732$

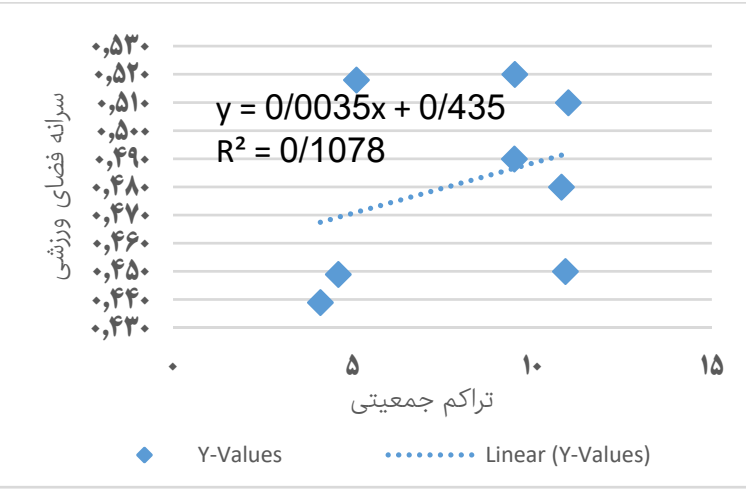

نمودار r) نسبت سرانه فضاهاى ورزشى روباز به تراكم جمعيت

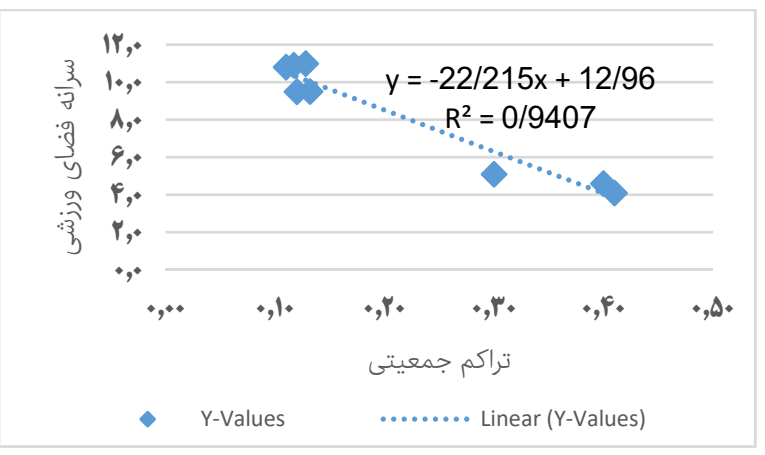

نمودار س) نسبت سرانه فضاهاى ورزشى سريوشيده به تراكم جمعيت 


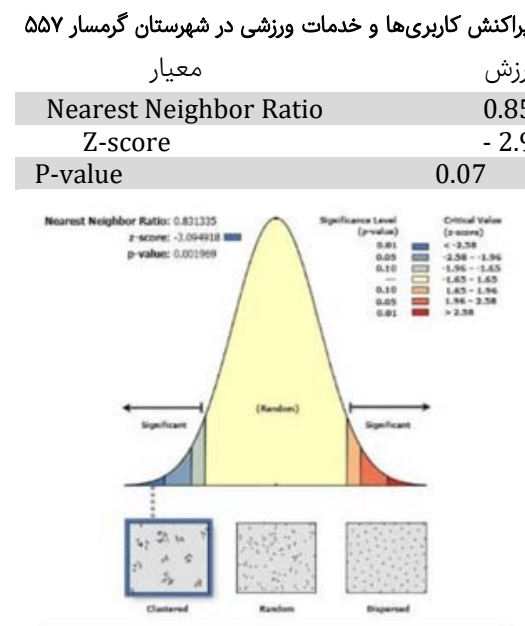

نمودار هِ) الكَى توزيع مراكز ورزشى روباز

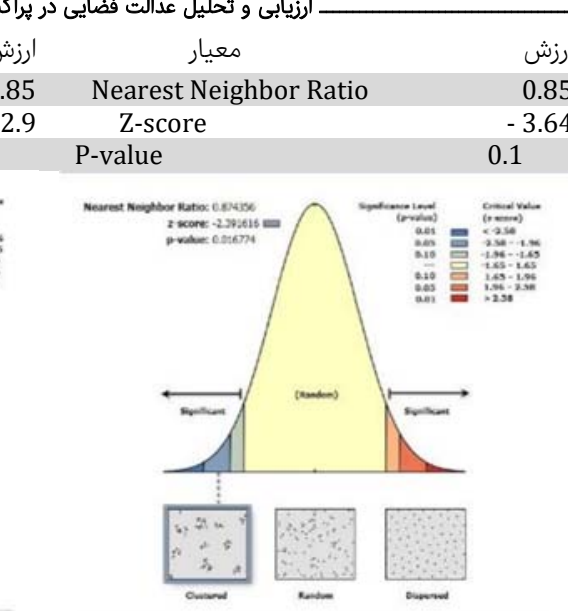

نمودار هب) الكَى توزيع مراكز ورزشى سريوشيده

\begin{tabular}{lc}
\multicolumn{1}{c}{ ارش } & \multicolumn{1}{c}{ ارش } \\
Nearest Neighbor Ratio & 0.85 \\
Z-score & -3.98 \\
P-value & 0.00
\end{tabular}

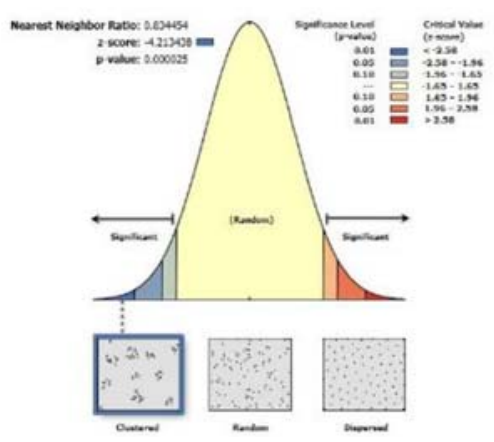

نمودار هآ) الكوى توزيع مراكز ورزشى

\section{نتيجه خيرى}

در حال حاضر يكى از مهمترين مشكلات موجود در اين شهرستان

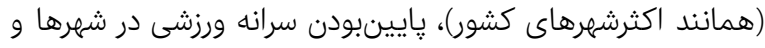

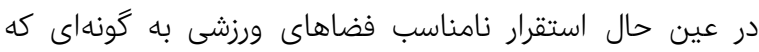

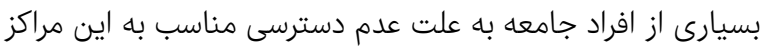
قادر به استفاده مطلوب از اماكن ورزشى نيستند. بنابراين؛ فضاهاى

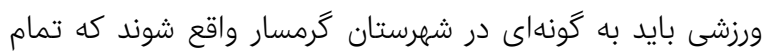

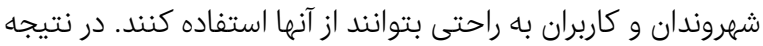
جهت افزايش كارايى اين مراكز توجه به ساماندهى و توزيع مناسي إناسب

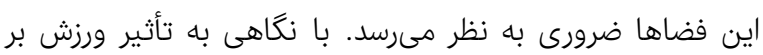
سلامتى جسمى و روانى و ميزان مشاركت مردم در ديكر كشورها

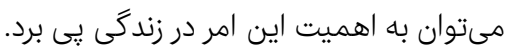

تشكر و قدردانى: موردى از سوى نويسندكان گزارش نشده است.

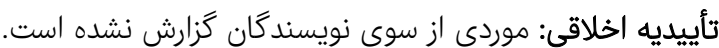

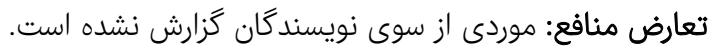

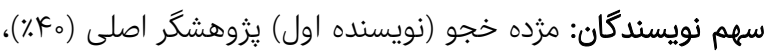

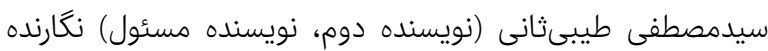

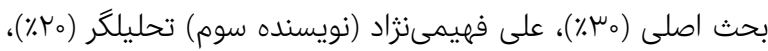

باقر مرسل (نويسنده جهارم) تحليلكَ (॰) (1\%).

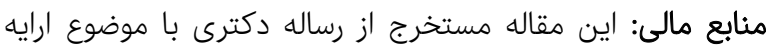

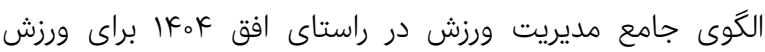
شهرستان گرمسار با بهرة مديرى از سيستم اطلاعات جغرافيايى است.

\section{منابع}

CESCS (2012). Council of europe social cohesion and sport examples of good practice from member countries of the committee for the development of sport .Lozun: CDDS.

Cleland V, Ball K, King AC, Crawford D (2010). Do the individual, social, and environmental correlates of physical activity differ between urban and rural women?
همانطور كه در نتايج تحقيق ارايه كرديد، سرانه فضاهاى ورزشى در

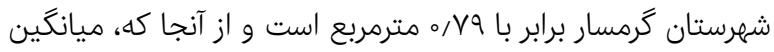

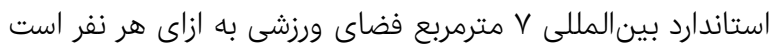

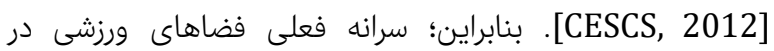
شهرستان كَرمسار از حداقل سرانه تعيين شده براى ايران نيز كمتر فئر

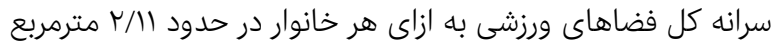

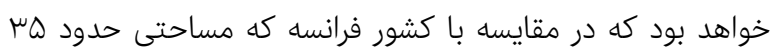

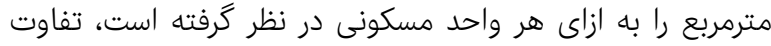
جشمخيرى وجود دارد. لازم به ذكر است كه تاكنون در ائر ايران ضابطه

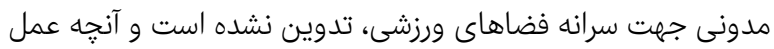

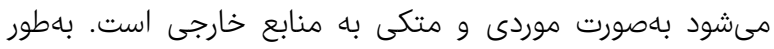

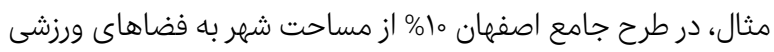
اختصاص داده شده كه رقم قابل توجهى بوده و در در حد معيارهاى

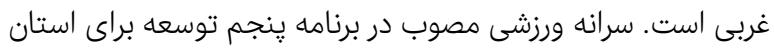

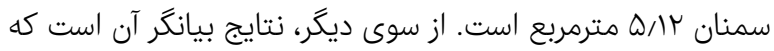

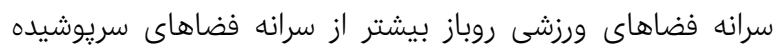

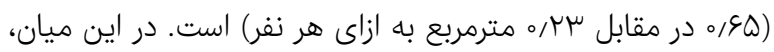

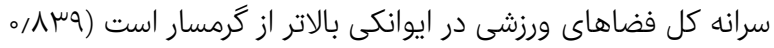

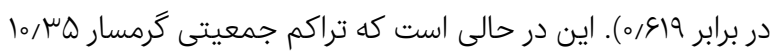

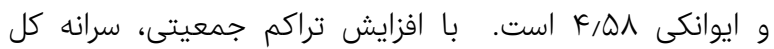

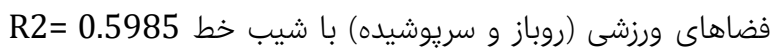

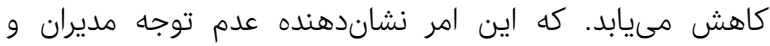

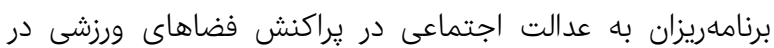

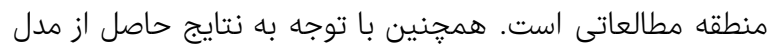
ميانكين نزديكترين همسايه مشخص شد كه الكوى فضايى توزيع

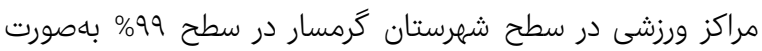

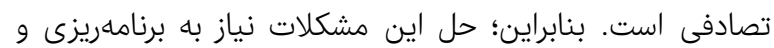

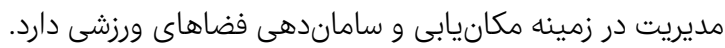


and deprivation in England 1960-2007. Geoforum. 43(1):44-57.

Namazi A, Hosseini SA (2018). Spatial analysis of sports venues and assessment of access to these centers according to their spatial distribution pattern at the communication network level. New Attitudes in Human Geography. 10(3):397-412 [Persian].

Oh K, Jeong S (2007). Assessing the spatial distribution of urban parks using GIS. Landscape and Urban Planning. 82(1):25-32.

Pacione M (2005). Urban geography a global perspective. $2^{\text {nd }}$ ed. London: Routledge

Peymanfar MH, Elahi A, Hamidi M (2012). A survey on obstacles to the development of public sports in the country. Social and Cultural Strategy. 1(3):145-155. [Persian]

Rasekh N, Sajadi N, Hamidi M, Khabiri M (2015). The design of a strategic plan for Iran female championships. Journal of Sport Management. 7(3):309-334. [Persian] Roostaei S, Babaei E, Kamelifar Z (2013). The assessment of spatial justice in the distribution of urban services. case study: Tabriz metropolis. Geographical Planning of Space journal. 3(10):82-101. [Persian]

Sohrabi P, Kashef MM Javadipour, M, Hosseini F (2011). An investigation of accessibility, closeness and building of sports areas in Uroumieh regarding standards. Journal of Sport Management. 3(10):5-25. [Persian]

SCI [Internet] (2019). Statistical center of Iran. [Published 2019, 15 August; Cited 2019, 27 May]. Available from: https://www.amar.org.ir/english

Tadjoeddin MZ, Suharyo WI, Mishra S C (2003). Aspiration to inequality: Regional disparity and center regional conflicts in Indonesia. Conference on Spatial Inequality in AASI. United Nations University Center. 2003, 28-29 March: Tokyo.

Tsou KW, YT Hung, YL Chang (2005) An accessibilitybased integrated measure of relative spatial equity in urban public facilities. Cities. 22(6): 424-435.

Vandian Z, Ebrahimi F (2013). Offering of suggestion model for site selection of sport place by incorporation multi-criteria decision making methods (MCDM) and geographic information system (GIS). Journal of Sport Management Research. 5(21):111-126. [Persian]
Environment and Behavior. 44(3):350-373.

Dixon J, Ramutsindela M (2006). Urban resettlement and environmental justice in Cape Town. Cities. 23(2):129139.

Ebrahimi A, Mehdipour A (2016). The effect of sport infrastructure and demographic characteristics on the level of sports participation of Ahwazi citizens using multilevel model (HLM). 5(17):83-98. [Persian]

Ebrahimzadeh I, Mojir Ardakani A (2006). An evaluation of land use in Ardakan city, Fars province. Geography and Development. 4(7):43-67. [Persian]

Hamidi M, Rajabi H, Alidoost Ghahfarokhi E, Zeinizadeh M (2018). Designing and developing a strategic plan of the Iranian student sport federation. Research in Educational Sport. 6(14):67-92. [Persian]

Hallmann K, Wicker P, Breuer C, Schuttoff U (2011). Interdependency of sport supply and sport demand in German metropolitan and medium-sized municipalitiesfindings from multi-level analyses. European Journal for Sport and Society. 8(1-2):65-84.

Hewko JN (2001). Spatial equity in the urban environment: Assessing neighborhood accessibility to public amenities. Canada: University of Alberta.

Hosseini SS, Kashef SM, Sayed Ameri M (2013). Locating port places using geographic information system (GIS); case study: Saqez City. Journal of Applied Research in Sport Management. 2(2):25-34. [Persian]

Humphreys BR, Ruseski JE (2010). The economic choice of participation and time spent in physical activity and sport in Canada. International Journal of Sport Finance. 10(2):138-159.

Kaphle I (2006). Evaluating people's accessibility to public parks using geographic information systems: A case study in Ames, Iowa. USA: Iowa State University.

Lotfi S, Koohsari Mohammad J (2009). Measuring objective accessibility to neighborhood facilities in the City a case study: Zone 6 in Tehran, Iran. Cities. 26(3):133-140.

Martinez J (2009). The use of GIS and indicators to monitor intra-urban inequalities a case Rosario, Argentina. Habitat International. 33(4):387-396.

Mitchel G, Norman P (2012). longitudinal environmental justice analysis: Co-evolution of environmental quality 